\title{
Challenges and opportunities for marketers in the emerging markets
}

\begin{abstract}
With increasing importance of the emerging markets in the global economy, there is growing interest among marketing researchers and managers to understand the differences between the consumers in the developed and emerging markets as well as the challenges and opportunities posed by these differences for both local and foreign marketers in these emerging markets. However, most recent research on consumer behavior and marketing strategy in the emerging markets uses concepts and theories developed and tested in the developed markets. Hence, it is not clear if these studies reflect the real picture of the consumers and marketers in the emerging markets by looking through the lens of developed markets. This special issue consists of twenty six papers, categorized along three broad themes (comparative marketing strategy, comparative consumer behavior, and emerging markets perspective), which not only extend the growing research on this important topic but also push the agenda for making the field of marketing into a truly global discipline, by not just merely replicating established theories and models but also identifying the limitations of the existing theories and extending these to provide fresh insights. This editorial also presents some useful directions for future research on this topic.
\end{abstract}

Keywords: consumers, cross-cultural, culture, developed, emerging, economies, marketing 


\section{Introduction}

'Emerging Markets' is a popular term now but it was introduced in 1981, by Antoine van Agtmael, an economist at International Finance Corporation (IFC), to represent a set of countries with promising stock-markets that could grow rapidly with investments (Economist, 2017). Since then, the scope of emerging markets has expanded, to include all those lower-income but rapid-growth economies that are using economic liberalization as their primary engine of growth (Hoskisson et al., 2000). Emerging markets fall into two broad groups: the developing countries in Asia, Latin America, Africa, and the Middle East, and the transition economies in the former Soviet Union and China (Hoskisson et al., 2000). Interestingly, despite making significant economic and social progress, most emerging markets still continue to suffer from periodic financial crises, credit defaults and economic slumps, hence there is a risk that they may remain 'emerging' and not achieve the same status as the 'developed' markets (Economist, 2017).

Early research on emerging economies focused mostly on the differences in the business and management strategies between developed and emerging markets, using diverse theoretical perspectives, such as institutional theory (Kirca, Fernandez, \& Kundu, 2016), transaction cost theory (Brouthers \& Brouthers, 2003), resource-based theory (Bortoluzzi et al., 2014), and agency theory (Wright et al., 2005). In the meantime, marketing researchers have also been interested in the emerging markets despite "obstacles and technical difficulties in applying research techniques in less-developed countries” (e.g., Boyd Jr et al., 1964). However, with recent advances in information and communication technologies that have flattened the world and brought consumers and marketers around the world closer to each other more than ever (Friedman, 2005), there is a renewed interest among marketing researchers to understand the differences between the consumers in the developed and emerging markets as well as the 
challenges and opportunities posed by these differences for both local and foreign marketers in these emerging markets (Guo, 2013; Kotabe \& Kothari, 2016; Sharma, 2011; Sheth, 2011).

Notwithstanding the above, most concepts and theories in consumer research and marketing strategy have been developed and tested in the existing developed markets and some of these have been replicated in the emerging markets. We argue that it is a very limited perspective because it colors our perceptions about the consumers and marketers in the emerging markets as seen through the cultural-institutional lens of the typical developed world context in which major marketing journals and their contributors operate. This is in stark contrast to the professional marketing community and multinational companies who are able to keep pace with the rapidly globalizing world economy, resulting in a regular exchange of consumer and market knowledge from the developed to the emerging markets and vice versa.

Based on the above, there seems to be a clear need to not only further extend but also develop a comprehensive conceptual framework to guide and structure the rapidly growing research on the challenges and opportunities faced by the marketers in the emerging markets. Moreover, it seems important for the future of marketing discipline that we reflect the real picture of the consumers and the markets in the emerging markets because they represent a large share of the world's population as well as economic growth. A stronger focus on emerging markets will thus help us push the theoretical boundaries of the marketing discipline and also provide significant practical benefits and managerial implications (Burgess \& Steenkamp, 2013).

In this special issue of the Journal of Business Research, we aim to push the agenda for making the field of marketing into a truly global discipline, by attracting not just mere replications of establish theories and models in the emerging markets, but fresh attempts to 
identify the limitations of the existing theories and to develop new or revised theories of consumer behavior and marketing strategy. We also note the relative paucity of research in the business-to-business (B2B) context in the emerging markets and address this gap in this special issue. In the next section, we categorize and briefly describe the twenty six articles included in this special issue, contributed by researchers with diverse backgrounds (e.g., consumer behavior, marketing strategy and econometric modeling) from all over the world.

\section{Challenges and Opportunities for Marketers in the Emerging Markets}

Early researchers tried to differentiate countries on the basis of simple criteria, such as their level of economic development (Rostow, 1960) or their size and the development of their middle classes (Dichter, 1962). Subsequent researchers developed more complex typologies with a diverse range of micro and macro variables (Samli \& Hassan, 1992). For example, researchers have identified three factors that shape consumption values of the consumers, which include level of economic development, political ideology, and business training and philosophy (Tse, Belk, \& Zhou, 1989). Researchers also argue that the basic lack of marketing infrastructure in the emerging markets (Arnold \& Quelch, 1998) has led to low market penetration, small market shares and poor profitability of foreign players in these markets (Dawar \& Chattopadhyay, 2002). Others recommend that multinationals should follow a balanced approach in the emerging markets, by focusing on both economic and social aspects of their operations, in order to maintain sustainable growth and avoid any pitfalls (Zhao, Park, \& Zhou, 2014).

In this context, recent research has highlighted the need to develop unique marketing strategies to address these challenges in order to help these markets realize their true potential (Kumar, Sunder, \& Sharma, 2015; Pels \& Sheth, 2017; Sheth, 2011). However, it is also 
interesting to note that the differences among the consumers in the developed and emerging markets are diminishing with time as the income levels and living standards rise in the emerging markets, resulting in higher levels of consumerism (Tse et al., 1989), materialism (Sharma, 2011) and cultural convergence (Jeon et al., 2016), and a concomitant rise in the number of middle class consumers (Kravets \& Sandikci, 2014). These new changes have resulted in calls for more conceptually sound, empirically robust and practically relevant research, in order to help us understand how the consumers and marketing mix elements in the emerging markets are similar to or different from those in the developed markets (Burgess \& Steenkamp, 2006). This special issue identifies and describes three main research streams on the challenges and opportunities for marketers in the emerging markets, as described in more detail in the next section.

\subsection{Comparative Marketing Strategy}

This research stream explores the differences in the impact of marketing strategies in the developed and emerging markets, such as advertising appeals (Zarantonello, Schmitt, \& Jedidi, 2014), internet and social media (Berthon et al., 2012), loyalty management programs (Kumar et al., 2013), product innovation (Sok, O'Cass, \& Miles, 2015), innovative services and firm capabilities (Bello et al., 2016). However, most of these studies focus on a specific context and as a result, there is still no broad conceptual framework to guide these differences. For example, Zarantonello et al. (2014) use a dataset of 257 television commercials from 23 countries to show that experiential (emotional) appeals have a stronger relationship with the components of brand knowledge in countries with medium and high gross domestic product (GDP) whereas global appeal has a stronger relationship with the components of brand knowledge in countries with low GDP. Similarly, Bello et al. (2016) study the impact of innovative services and firm capabilities on the performance of professional service firms from emerging markets. This special issue 
addresses the need for broader conceptual frameworks to explain the differences in marketing strategies between the developed and emerging markets, with two invited articles (Sinha \& Sheth, 2017; Varadarajan \& Kaul, 2017) and six others (Agarwal et al., 2017; Anning-Dorson, 2017; Cherrier, Goswami, \& Ray, 2017; Heinberg, Ozkaya, \& Taube, 2017; Kadic-Maglajlic, Boso, \& Micevski, 2017; Roy et al., 2017).

In the first invited article, titled "Growing the Pie in Emerging Markets: Marketing Strategies for Increasing the Ratio of First-Time Users to Non-Users”, Sinha and Sheth (2017) identify emerging markets as the growth engines of the world and argue that many multinationals flounder in these countries due to the challenges posed by their five key market characteristics: market heterogeneity, sociopolitical governance, unbranded competition, chronic shortage of resources and inadequate infrastructure. Reducing the adverse impact of these unique characteristics can help grow the market size by converting non-users into first-time users using eight marketing strategies, which include improving affordability through democratizing and upscaling the offer; accessibility through managing and reinventing reach; acceptability through cultural and functional fusion; and awareness through building brand identity and engaging stakeholders. Achieving these customer-centric outcomes can help multinational companies overcome the challenges faced by them in the emerging markets and realize their true potential.

In the second invited article titled 'Doing Well by Doing Good Innovations for Emerging Markets', Varadarajan and Kaul (2017) define the notion of Doing well by doing good (DWDG) innovations, as "the implementation of new products, processes and practices, and modifications of existing products, processes and practices by firms that benefit society by contributing toward alleviation of specific social problems, and enhancing performance of firms”. Social problems may arise from gaps in the quality and quantity of public goods (e.g., education, electricity and 
water) as well as gaps in affordability, awareness, availability, and adoptability of private goods. This invited article also offers a framework to organize potential opportunities for DWDG innovations, which could help alleviate specific social problems in the emerging and less developed markets, in terms of both short and long-term as well as quantifiable and nonquantifiable benefits to the society and to the firm.

The next article by Agarwal et al. (2017), “Market Driving at the Bottom of the Pyramid (BoP): An Analysis of Social Enterprises from the Healthcare Sector" continues the above theme by addressing the lack of research on external dimensions of market driving for the purposes of 'societal change' in both developed and emerging markets. This paper uses a multiple case-study method to explore how social enterprises at the Bottom of the Pyramid (BoP) in healthcare sector could use their regulative, normative and cognitive legitimacies to trigger societal change in the emerging markets. The authors argue that such market driving through societal change can lead to the construction of new and more inclusive healthcare services in the emerging markets.

On a related theme, Cherrier et al. (2017) draw on institutional complexity, social movement and paradox theories, to examine the opportunities for social entrepreneurship using an ethnographic case study of a social venture in India, in their article titled, "Social Entrepreneurship: Creating Value in the Context of Institutional Complexity”. The authors find that institutional complexity manifests itself in the form of overlapping and/or contradictory institutional logics, which in turn provokes paradoxical tension. They also identify four strategic responses to institutional complexity (appropriation, integration, differentiation, and workingthrough), which enable the social enterprises to reach out to a broad range of stakeholders. Overall, the authors argue that institutional complexity in the emerging markets can actually be a useful resource in a dynamic process of social value creation. 
The next four articles in this section move away from social enterprises and explore the differences in marketing strategies for conventional business-to-consumer firms. For example, Heinberg et al. (2017) explore the similarities and differences in the impact of corporate image and reputation on brand equity for the consumers in the emerging markets, in their article titled, “Do corporate image and reputation drive brand equity in India and China? - Similarities and differences”. According to these authors, corporate signals (e.g., image and reputation) can help marketers reduce consumer uncertainty about their brands in the emerging markets and help enhance brand equity. Using two large samples of consumers in India $(n=554)$ and China $(n=1180)$, they find that the perceived uncertainty towards brands differs between emerging markets and this difference is shaped by the institutional background in the country, which in turn affects the effectiveness of corporate signals.

In the article "Customer Involvement Capability and Service Firm Performance: The Mediating Role of Innovation” (Anning-Dorson, 2017) explores the differences in the influence of firm-level customer involvement capabilities on service firm performance and the mediating role of innovation in this process, between service firms operating in a developed (United Kingdom) and an emerging (Ghana) market. The authors find that customer involvement capability has a positive relationship with service firm performance in Ghana and a negative relationship in United Kingdom, but innovation (both product and process) mediates these relationships between involvement capability and firm performance in both the contexts. Hence, the effect of firm-level capability seems to be context-specific, which is an important implication for service firms operating in both developed and emerging markets.

Next, Roy et al. (2017) highlight the importance of managing customer engagement behavior (CEB) for firms to build and sustain long-term customer-firm relationships in their 
article, titled "Customer engagement behavior in individualistic and collectivistic markets". This study examines four different roles of customer engagement behaviors (augment, co-develop, influence, and mobilize) as well as the relationships among service fairness, trust (cognitive and affective), value-in-use (ViU) and CEB. Results from two developed (USA and Australia) and two emerging (India and China) markets suggest that CEB is a higher-order construct, with a consistent structure across the developed and emerging markets. However, service fairness seems to have a stronger influence on affective trust in the emerging (vs. developed) markets. Therefore, multinational service providers need to use customer engagement behaviors and treat their customers in the emerging markets fairly in order to build cognitive and affective trust with them and by understanding how these customers create value-in-use.

Finally, in their article "How internal marketing drive customer satisfaction in matured and maturing European markets?”, Kadic-Maglajlic et al. (2017) examine the differences in the effects of internal marketing on customer satisfaction, mediated by salesperson cross-functional goal compatibility, at varying levels of salesperson cross-functional connectivity, for developed and emerging markets. Using data from salespeople in a large financial services firm operating in both, developed (Central Europe - Austria, Croatia, Slovenia) and emerging (South and Eastern Europe - Bosnia and Herzegovina, Moldova and Romania) markets, this study finds support for the mediating role of cross-functional goal compatibility in the effect of internal marketing on customer satisfaction in both markets. In addition, at high levels of cross-functional connectivity, the effect of goal compatibility on customer satisfaction is strengthened in maturing markets.

All the eight papers in this section, highlight the importance of understanding the differences in the effectiveness of marketing strategies between the developed and emerging markets due to various socio-economic, cultural and institutional factors, for multinational firms 
that operate in both these types of markets and the need to incorporate these differences in their marketing plans, in order to ensure optimal utilization of their scarce resources. In other words, one of the most important learning from all these studies is that multinational firms should acknowledge that there is no single definition of emerging markets and each of these markets is different from not only the developed markets but also from each other.

\subsection{Comparative Consumer Behavior}

This body of research focuses on the cultural, demographic and socio-economic differences between the consumers in the emerging and developed markets, as reflected in their unique characteristics, values, attitudes and behaviors (e.g., Maheswaran \& Shavitt, 2000; Michaelidou et al., 2015; Morgeson, Sharma, \& Hult, 2015; Sharma, 2011). For instance, Maheswaran and Shavitt (2000) highlight the cultural differences between the consumers in developed and emerging markets and call for more research in this area. Many researchers have responded to these calls by exploring the differences in consumer behaviors between developed and emerging markets in the last decade or so. For example, Sharma (2011) explored the contrasting impact of materialism and value-consciousness on country-of-origin effects for

consumers in developed and emerging markets. More recently, Michaelidou et al. (2015) explore the cross-cultural and cross-national differences in consumer psychology and behaviors in general, while Morgeson et al. (2015) study cross-national differences in consumer satisfaction with mobile services in emerging and developed markets.

Notwithstanding the important contribution of all these studies, there is now growing research focus on the attitudes and behaviors of the consumers in the emerging markets per se, rather than on their comparison with the consumers in the developed markets. Hence, it is not 
surprising to see only four articles in this special issue on this theme, comparing the attitudes and behaviors of consumers in the developed and emerging markets with and among each other (Dermody et al., 2017; Diallo \& Seck, 2017; Horváth \& Adıgüzel, 2017; Lu et al., 2017).

The first paper in this section, "Shopping enjoyment to the extreme: Hedonic shopping motivations and compulsive buying in developed and emerging markets”, Horváth and Adıgüzel (2017) find significant differences in the relationship between hedonic shopping motivations and compulsive buying using a study with 520 female shopping mall visitors in two developed (the Netherlands and Germany) and two emerging (Turkey and Russia) markets. Specifically, they find that gratification seeking, idea shopping and role play drive compulsive buying in the developed markets, whereas adventure seeking is the main motivation in the emerging markets. Moreover, role play has a negative effect on compulsive buying in the emerging markets.

Next, in their paper, "How store service quality affects attitude toward store brands in emerging countries: Effects of brand cues and the cultural context”, Diallo and Seck (2017) investigate the impact of store brand perceptual cues and cultural differences on the relationships between service quality and attitude toward store brands, using data from two emerging markets (Brazil and Vietnam). They find that both positive and negative perceptual brand cues mediate the effects of overall service quality, store physical aspects, store reliability, and personnel attention on attitude toward store brands. Perceived price and functional risk mediate these effects in both countries investigated, but store brand perceived value and financial risk do not. Moreover, the effects of overall service quality, store physical aspects, and store personnel attention on attitude toward store brands are stronger in Brazil than in Vietnam. However, the effect of store reliability does not differ across countries. Overall, this study shows significant differences but also many similarities between consumers in these two large emerging markets. 
On a similar theme, Lu et al. (2017) examines the impact of cross-national variation in culture on the selection of retail channels in a multichannel environment in their paper, "Crossnational variation in consumers' retail channel selection in a multichannel environment: Evidence from Asia-Pacific countries”, using actual purchase decisions via online and telephone channels by consumers in eight Asia-Pacific countries. They find that consumers in countries with high uncertainty avoidance and long-term orientation are less likely to adopt online channels rather than telephone channels, whereas countries with high individualism, high masculinity, and high indulgence are more likely to adopt online channels. These findings highlight the importance of cross-national variation of culture on retail channel selection.

Finally, Dermody et al. (2017) use intra-personal influences and situational cueing to explore the influence of Pro-environmental Self-Identity (PESI) on the sustainable buying and curtailment behaviors of consumers in China and Poland, in their paper "Appraising the Influence of Pro-environmental Self-Identity on Sustainable Consumption Buying and Curtailment in Emerging Markets: Evidence from China and Poland”. They find that PESI is activated by situational cueing, moral responsibility, assessment, social desirability tinted by consumer effectiveness and knowledge. These findings have important implications for ecoinnovation as well as policy-making in emerging markets because consumers with high levels of PESI could potentially play an active stakeholder role in this context.

Overall, all these papers highlight the importance of exploring the differences in the impact of national culture and economic conditions on consumer motivations, attitudes and behaviors, between the developed and emerging markets, for both academic researchers and marketing managers. However, it is also important to understand the theoretical reasons for these differences and to try and develop stronger conceptual frameworks to guide future research. 


\section{$2.3 \quad$ Emerging markets perspective}

This research stream examines the consumers and marketers in the emerging markets for who they are and not necessarily compare them with those in the developed markets, as reflected by the impact of product-market strategies (Wei, Samiee, \& Lee, 2014), unique behaviors of the consumers at the base-of-the-pyramid (Christensen, Siemsen, \& Balasubramanian, 2015), emergence of a global cultural identity (Strizhakova, Coulter, \& Price, 2012), role of countrymarket characteristics (Bahadir, Bharadwaj, \& Srivastava, 2015) and consumer prior knowledge (Sun et al., 2017), growing importance of new middle-class consumers (Kravets \& Sandikci, 2014) and differences in the attitudes of consumers in the emerging markets towards local and international brands (Tanusondjaja et al., 2015). This has become the most fertile research stream in recent years as more and more researchers begin to investigate the unique characteristics, motivations, attitudes and behaviors of the consumers in individual emerging markets.

In this context, it is not surprising to see that more than half the papers in this special issue are devoted to exploring the emerging markets perspective of consumer behavior and marketing strategies, although most of these focus on the two largest emerging markets, namely China (Berger et al., 2017; Huang \& Wang, 2017; Jiang, Luk, \& Cardinali, 2017; Lee et al., 2017) and India (Dholakia, Dholakia, \& Chattopadhyay, 2017; Fletcher-Brown, Pereira, \& Nyadzayo, 2017; Jaikumar, Singh, \& Sarin, 2017; Mishra et al., 2017; Nyadzayo, Matanda, \& Rajaguru, 2017) and only a few studies from the other emerging markets in Africa (Shamah et al., 2017), Russia (Smirnova, Rebiazina, \& Frösén, 2017), Turkey (Duman \& Ozgen, 2017) and Vietnam (Nguyen, Westberg, et al., 2017; Nguyen, Özçaglar-Toulouse, \& Kjeldgaard, 2017). 


\subsubsection{China}

The first two papers on China focus on Guanxi, the unique social mechanism that Chinese firms rely on to build the individual relationship connections that help them influence others and secure scarce resources (Berger et al., 2017; Lee et al., 2017). First, Berger et al. (2017) reveal a paradox in the Chinese market that mostly relies on a mutually beneficial social guanxi ties to drive businesses, the diamond industry is characterized by a rather antagonistic arms-length approach, similar to the one adopted by businesses in traditional Western cultures. For example, interpersonal trust (Xinren) has a positive influence on emotional attachment (Ganqing) and obligational favor (Renqing), but has a direct negative influence on performance (i.e., the paradox). Ganqing also has a positive influence on performance and Renqing leads to greater satisfaction that in turn has a positive effect on performance. The next paper by Lee et al. (2017) uses the ‘cognition-affect-conation' linkage to demonstrate important differences in the impact of guanxi and conventional relationship marketing methods on customer loyalty and word-of-mouth intentions, and the mediating role of calculative trust and affective attitude toward the service provider in this process, with a field-survey of Chinese retail-banking customers $(\mathrm{N}=420)$. Both these papers extend our current understanding of the well-known Guanxi phenomenon and provide fresh insights into its changing nature and its impact.

Huang and Wang (2017) explore the relationship between social identity and conspicuous consumption for the migrant workers, a new large consumer segment in China, which is a result of rapid urbanization and has led to new opportunities and challenges to multinational marketers of branded products. Their findings show that the conspicuous (branded products) consumption by these migrant workers is mainly driven by a 'bandwagon' effect, under the influence of their desire to be associated with their aspirational reference groups, whereas the more privileged 
consumers may engage in conspicuous consumption to disassociate from the crowd. They also find that subjective norms mediate the impact of conspicuous consumption on purchase intention of branded products and traditional Chinese cultural values moderate some of these effects. In a similar vein, Jiang et al. (2017) integrate the theories of brand touchpoints and brand experience to explore the combined effect of pre-consumption and consumption experiences on customer perceived value (CPV) and brand preference, in the context of retail cosmetics market in China. Their results show that favorable experience with the brand's marketing communication activities during the pre-consumption stage helps generate a positive affective responses, which in turn lead to greater brand preference, perceived value and brand loyalty. This study extends the conceptualization of consumption-based evaluation of perceived value of service brands to include the consideration of pre-consumption experience, especially in the emerging markets.

\subsubsection{India}

In the first paper on the emerging Indian market, Jaikumar et al. (2017) explore the motivations around conspicuous consumption using the data from a panel of 34,621 households from India Human Development Surveys (2004 and 2011). They find that higher conspicuous consumption may lead to higher subjective economic well-being (SEWB) and this effect is higher for the Bottom of the pyramid (BOP) households. These findings indicate a strong urge for upward social mobility among event he poorest consumers in an emerging market like India, which could pose a threat to the socio-economic and political stability of the country, unless it is channeled in a positive manner, by providing new jobs and other opportunities for income generation for the growing numbers of young consumers in India. At the other end of Indian socio-economic hierarchy, Mishra et al. (2017) identify teenagers as the major contributors of online content and electronic word-of-mouth (eWOM) because of continuous communication 
and sharing with peers using social media or instant messaging apps, including telling them about their purchases and consumption experiences. A field survey with high school students in India, show that normative and informative influence of peers and the Internet not only have direct positive association with eWOM but also mediate the direct effects of age and Internet usage on eWOM. Moreover, eWOM behavior of male teenagers is influenced by current peer norms, whereas the credibility of online information is more critical for female teenagers. These insights are important for marketers who would like to target the rapidly growing teenage consumer segment, especially in emerging markets like India.

The next three papers in this section investigate broader issues related to different segments of the rapidly growing Indian market. Dholakia et al. (2017) use extensive fieldwork with observations, interviews and secondary research, to present a multifaceted view of the highly fragmented Indian retail sector, showing that consumer patronage of small traditional stores provides competitive advantages to them against their much larger competitors. FletcherBrown et al. (2017) use signaling theory to uncover the socio-economic, cultural and institutional challenges and opportunities faced by health marketers and consumers in dealing with breast cancer awareness (BCA) in India. Findings from focus groups with medical professionals and interviews with women using an interpretive-inductive method and a grounded theory approach, show complex challenges at national, state and community levels which negatively affect the reputation of Indian public health sector. The authors suggest the use of social marketing strategies to raise awareness about breast cancer through community health activists. Finally, Nyadzayo et al. (2017) use a field survey of franchisee businesses in India to identify perceived franchisor competence and level of information sharing as drivers of the franchisees' emotional brand attachment, perceived relationship value and brand loyalty towards the franchisors. 


\subsubsection{Other emerging markets}

Shamah et al. (2017) show a positive impact of customers' self-congruity on their loyalty towards fast-food restaurants and the mediating role of key fast food choice cues (environment, service, product, and price) with a sample of North African (Egypt and Morocco) consumers. Smirnova et al. (2017) combine insights from in-depth interviews with industry experts with three sets of survey data to identify two distinct dimensions (customer-centric strategy and customer service delivery) of customer orientation (CO) in the emerging market of Russia. The authors find that both these dimensions contribute to the firms' ability to serve their customers, to adapt to their market environment, and to optimize their market growth and profitability; but their relative impact varies across different types of performance outcomes, hence it is important to manage both these dimensions to improve the firms’ overall business performance. Duman and Ozgen (2017) use theories of brand avoidance and political consumerism to explore the punishing/rewarding of brands associated to a political ideology (BAPI) by the customers in Turkey, with two empirical studies. Findings show that consumers punish the brands they oppose politically because they do not perceive any self-congruity with them and believe that these brands harm the societal well-being by polarizing it and making it more conservative. Moreover, religious commitment does not have a significant effect on consumer attitudes and willingness to punish/reward BAPI but consumers who attend religious services are likely to punish BAPI.

The last two papers in this special issue explore the consumer behavior in a new emerging market, Vietnam. First, Nguyen, Westberg, et al. (2017) explore the role of extended family in family decision-making for high-involvement purchase decisions in Vietnam. Using a grounded theory approach with 33 in-depth interviews involving 11 families across Vietnam, including both nuclear and extended family members, the authors find that parents continue to 
maintain a significant role in the consumption decision-making of their adult children, by acting as facilitators, cultural mentors and/or patriarchs. However, these roles, when combined with the changing macro-economic environment, may lead to a conflict between the younger generation's respect and deference to their parents and their own aspirations fueled by socio-economic change. Moreover, female consumers are aspiring to gain a greater say in family decisionmaking in the face of well-entrenched cultural norms of a traditional patriarchal society.

Finally, Nguyen, Özçaglar-Toulouse, et al. (2017) explore the development and expression of self-identity by young Vietnamese consumers through their everyday consumption practices. Findings from in-depth interviews and observations suggest that consumption leads to reflexive self-awareness about the young consumers' competences, body sensitivities, and distinctive tastes in response to the control exerted by the government. Young Vietnamese consumers also seem to "use their everyday consumption practices to achieve individualization through self-emancipation, self-enrichment, and self-actualization, and to achieve socialization through self-authentication and self-cultivation”. Hence, young Vietnamese consumers appear to reject the communist identity and the lifestyles promoted by the government, which is somewhat similar to the experience of Chinese consumers with the rapid growth in Chinese economy.

Overall, the fourteen articles in this section provide fresh insights into the unique characteristics of many emerging markets, ranging from China, India and Russia to Egypt, Morocco, Turkey and Vietnam. While some of these articles focus on specific consumer segments, such as young consumers (Mishra et al., 2017; Nguyen, Özçaglar-Toulouse, et al., 2017) or consumption contexts, such as conspicuous consumption (Huang \& Wang, 2017; Jaikumar et al., 2017), others explore the changing face of traditional phenomena, such as Guanxi in China (Berger et al., 2017; Lee et al., 2017). From the findings reported in these 
papers, it is clear that there is a need for even more research into the unique aspects of consumer behaviors and marketing strategies in individual emerging markets, not only to help understand these but to also possibly cross-fertilize these ideas into other emerging markets, so that they can learn from each other's experiences. Such an approach would also help marketing researchers develop fresh ideas based on the real experience of consumers and marketers in the emerging markets and not just rely on the concepts, models and theories used in the developed markets.

\section{Open questions and future research}

Notwithstanding the useful contributions made by the twenty six articles in this special issue, there are still some research areas that remain largely unaddressed and demand more attention in future research. First, it is still not clear if the traditional consumer decision-making models that were developed with the consumers in the Western developed countries would apply to the study of consumers in the emerging markets. For example, the traditional consumer decision-making models include the influence of reference groups and social networks on information search, alternative evaluation and purchase behaviors, but the nature of these reference groups and social networks may vary widely between the developed and emerging markets and even among the different emerging markets. We need more research into such areas so as to move towards more comprehensive conceptual frameworks that can incorporate and explain these differences among diverse groups of consumers around the world.

Second, although many articles in this special issue take a critical look at the existing marketing concepts, models and theories, when applying these in the context of emerging markets; we need even more efforts to develop new constructs and relationships to explain consumer or organizational buying behaviors in the emerging markets. In this context, future 
studies could focus on identifying the unique features of the marketing mix elements in the emerging markets such as product features, packaging, advertising, branding, distribution and disposal; as well as the implications of these unique features for the marketers in these markets This may also include the impact of new media and technologies such as smartphones, broadband and mobile internet, social media and ecommerce, on the attitudes and behaviors of the consumers and firms in the emerging markets, possibly across different demographic cohorts.

Next, we need more research on the moderating influences of the institutional, socioeconomic, cultural and other variables on the relationship between consumer and managerial attitudes and behaviors, which would help identify the unique marketing research tools and techniques that are or should be used in the emerging markets. This will not only provide useful insights about the consumers and marketing managers in the emerging markets but could also explore the applicability of these tools and techniques in the erstwhile developed markets.

Finally, most of the articles included in this special issue address the topics that were mentioned in the call for papers, however many of those topics still remain relevant but attended. The following topics should provide useful avenues for future research on the 'challenges and opportunities for marketers in the emerging markets':

- Product: New product development, product lifecycle management, product innovation and enhancement, innovation diffusion and new product adoption.

- Price: Pricing models and rules, price mechanisms (peak vs. off-peak, bundling etc.), differences in taxation and regulations. 
- Promotion: Impact of standardized versus localized promotion strategies, nature and reach of different media vehicles, influence of different types of advertising appeals and message framing, unique features of advertising and media agencies.

- Place: Local formal vs. informal distribution channels and their unique characteristics, role of channel partners and channel conflict, integrating local and global supply chains, business process outsourcing and its implications.

- People: Availability of trained sales and marketing professionals and agencies, recruitment and training processes and issues.

- Processes: State of process orientation in the emerging markets especially in the unorganized sectors, bottlenecks in creating and managing businesses such as bureaucracy, red tape and other restrictive practices.

- Marketing Strategy - segmentation and targeting of individual and institutional consumers in the emerging markets and the positioning of local and global brands.

- Reasons for failure and success of local and global marketers in the emerging markets, developing analytical models to predict such failure or success.

- Consumer reactions to globalization and global consumer culture in the emerging markets; rise of consumer movements and customer protection regulations.

- Dark side of emerging markets - copyright violations, corruption, bribery, counterfeit products, nepotism and cronyism, political connections. 
- Rise of sustainable marketing and corporate social responsibility in the emerging markets, role of social entrepreneurs and not-for-profit segment

\section{Acknowledgments}

The guest co-editors are grateful to the two chief editors of the Journal of Business Research, Anders Gustafsson and Naveen Donthu, for their continuous support and guidance during the long journey of planning and executing this special issue. We also thank all the submitting authors for their overwhelming response to the call for this special issue, resulting in 150 submissions out of which we were able to finally accept 26 articles, which together make a very useful contribution to our knowledge about the opportunities and challenges for marketers in the emerging markets. Finally, we thank the more than 100 reviewers who helped us by agreeing to review the papers and shared their timely and constructive comments with the submitting authors. We are unable to mention all their names due to space constraint but we are sure they would understand and acknowledge our deepest gratitude for their kind help.

\section{References}

Agarwal, N., Chakrabarti, R., Brem, A., \& Bocken, N. (2017). Market driving at Bottom of the Pyramid (BoP): An analysis of social enterprises from the healthcare sector. Journal of Business Research, . (in this issue).

Anning-Dorson, T. (2017). Customer involvement capability and service firm performance: The mediating role of innovation. Journal of Business Research, (in this issue).

Arnold, D. J., \& Quelch, J. A. (1998). New strategies in emerging markets. MIT Sloan Management Review, 40(1), 7-20. 
Bahadir, S. C., Bharadwaj, S. G., \& Srivastava, R. K. (2015). Marketing mix and brand sales in global markets: Examining the contingent role of country-market characteristics. Journal of International Business Studies.

Bello, D. C., Radulovich, L. P., Javalgi, R. R. G., Scherer, R. F., \& Taylor, J. (2016). Performance of professional service firms from emerging markets: Role of innovative services and firm capabilities. Journal of World Business, 51(3), 413-424.

Berger, R., Herstein, R., Silbiger, A., \& Barnes, B. R. (2017). Is guanxi universal in China? Some evidence of a paradoxical shift. Journal of Business Research, (in this issue).

Berthon, P. R., Pitt, L. F., Plangger, K., \& Shapiro, D. (2012). Marketing meets Web 2.0, social media, and creative consumers: Implications for international marketing strategy. Business horizons, 55(3), 261-271.

Bortoluzzi, G., Chiarvesio, M., Di Maria, E., \& Tabacco, R. (2014). Exporters moving toward emerging markets: a resource-based approach. International Marketing Review, 31(5), 506-525.

Boyd Jr, H. W., Frank, R. E., Massy, W. F., \& Zoheir, M. (1964). On the use of marketing research in the emerging economies. Journal of Marketing Research, 1(4), 20-23.

Brouthers, K. D., \& Brouthers, L. E. (2003). Why service and manufacturing entry mode choices differ: The influence of transaction cost factors, risk and trust. Journal of Management Studies, 40(5), 1179-1204. 
Burgess, S. M., \& Steenkamp, J.-B. E. M. (2006). Marketing renaissance: How research in emerging markets advances marketing science and practice. International Journal of Research in Marketing, 23(4), 337-356.

Burgess, S. M., \& Steenkamp, J.-B. E. M. (2013). Editorial: introduction to the special issue on marketing in emerging markets. International Journal of Research in Marketing, 30(1), $1-3$.

Cherrier, H., Goswami, P., \& Ray, S. (2017). Social entrepreneurship: Creating value in the context of institutional complexity. Journal of Business Research, (in this issue).

Christensen, L. J., Siemsen, E., \& Balasubramanian, S. (2015). Consumer behavior change at the base of the pyramid: Bridging the gap between for-profit and social responsibility strategies. Strategic Management Journal, 36(2), 307-317.

Dawar, N., \& Chattopadhyay, A. (2002). Rethinking marketing programs for emerging markets. Long Range Planning, 35(5), 457-474.

Dermody, J., Koenig-Lewis, N., Zhao, A. L., \& Hanmer-Lloyd, S. (2017). Appraising the influence of pro-environmental self-identity on sustainable consumption buying and curtailment in emerging markets: Evidence from China and Poland. Journal of Business Research, (in this issue).

Dholakia, R. R., Dholakia, N., \& Chattopadhyay, A. (2017). Indigenous marketing practices and theories in emerging economies: Consumer behavior and retail transformations in India. Journal of Business Research, (in this issue). 
Diallo, M. F., \& Seck, A. M. (2017). How store service quality affects attitude toward store brands in emerging countries: Effects of brand cues and the cultural context. Journal of Business Research, (in this issue).

Dichter, E. (1962). The World Customer. Harvard Business Review, 40(July-August), 119-121.

Duman, S., \& Ozgen, O. (2017). Willingness to punish and reward brands associated to a political ideology (BAPI). Journal of Business Research, (in this issue).

Economist. (2017). What's in a name? Defining emerging markets - A self-fulfilling prophecy. from https://www.economist.com/news/special-report/21729866-self-fulfilling-prophecydefining-emerging-markets

Fletcher-Brown, J., Pereira, V., \& Nyadzayo, M. W. (2017). Health marketing in an emerging market: The critical role of signaling theory in breast cancer awareness. Journal of Business Research, (in this issue).

Friedman, T. L. (2005). The world is flat: A brief history of the twenty-first century: Macmillan.

Guo, X. (2013). Living in a global world: Influence of consumer global orientation on attitudes toward global brands from developed versus emerging countries. Journal of International Marketing, 21(1), 1-22.

Heinberg, M., Ozkaya, H. E., \& Taube, M. (2017). Do corporate image and reputation drive brand equity in India and China? Similarities and differences. Journal of Business Research, (in this issue). 
Horváth, C., \& Adıgüzel, F. (2017). Shopping enjoyment to the extreme: Hedonic shopping motivations and compulsive buying in developed and emerging markets. Journal of Business Research, (in this issue).

Hoskisson, R. E., Eden, L., Lau, C. M., \& Wright, M. (2000). Strategy in Emerging Economies. Academy of Management Journal, 43(3), 249-267.

Huang, Z., \& Wang, C. L. (2017). Conspicuous consumption in emerging market: The case of Chinese migrant workers. Journal of Business Research, (in this issue).

Jaikumar, S., Singh, R., \& Sarin, A. (2017). 'I show off, so I am well off': Subjective economic well-being and conspicuous consumption in an emerging economy. Journal of Business Research, (in this issue).

Jeon, H. J., Meiseberg, B., Dant, R. P., \& Grünhagen, M. (2016). Cultural Convergence in Emerging Markets: The Case of McDonald's in China and India. Journal of Small Business Management, 54(2), 732-749.

Jiang, K., Luk, S. T.-k., \& Cardinali, S. (2017). The role of pre-consumption experience in perceived value of retailer brands: Consumers' experience from emerging markets. Journal of Business Research, (in this issue).

Kadic-Maglajlic, S., Boso, N., \& Micevski, M. (2017). How internal marketing drive customer satisfaction in matured and maturing European markets? Journal of Business Research, (in this issue). 
Kirca, A. H., Fernandez, W. D., \& Kundu, S. K. (2016). An empirical analysis and extension of internalization theory in emerging markets: The role of firm-specific assets and asset dispersion in the multinationality-performance relationship. Journal of World Business, 51(4), 628-640.

Kotabe, M., \& Kothari, T. (2016). Emerging market multinational companies’ evolutionary paths to building a competitive advantage from emerging markets to developed countries. Journal of World Business, 51(5), 729-743.

Kravets, O., \& Sandikci, O. (2014). Competently ordinary: New middle class consumers in the emerging markets. Journal of Marketing, 78(4), 125-140.

Kumar, V., Sharma, A., Shah, R., \& Rajan, B. (2013). Establishing profitable customer loyalty for multinational companies in the emerging economies: a conceptual framework. Journal of International Marketing, 21(1), 57-80.

Kumar, V., Sunder, S., \& Sharma, A. (2015). Leveraging distribution to maximize firm performance in emerging markets. Journal of Retailing, 91(4), 627-643.

Lee, L. W. Y., Tang, Y., Yip, L. S. C., \& Sharma, P. (2017). Managing customer relationships in the emerging markets-guanxi as a driver of Chinese customer loyalty. Journal of Business Research, (in this issue).

Lu, Q. S., Pattnaik, C., Xiao, J., \& Voola, R. (2017). Cross-national variation in consumers' retail channel selection in a multichannel environment: Evidence from Asia-Pacific countries. Journal of Business Research, (in this issue). 
Maheswaran, D., \& Shavitt, S. (2000). Issues and New Directions in Global Consumer Psychology. Journal of Consumer Psychology, 9(2), 59-66.

Michaelidou, N., Reynolds, N., Greenacre, L., \& Hassan, L. M. (2015). Cross-cultural and crossnational consumer research: psychology, behavior and beyond. International Marketing Review, 32(3/4).

Mishra, A., Maheswarappa, S. S., Maity, M., \& Samu, S. (2017). Adolescent's eWOM intentions: An investigation into the roles of peers, the Internet and gender. Journal of Business Research, (in this issue).

Morgeson, F. V., III, Sharma, P. N., \& Hult, G. T. M. (2015). Cross-National Differences in Consumer Satisfaction: Mobile Services in Emerging and Developed Markets. Journal of International Marketing, 23(2), 1-24.

Nguyen, H. L., Westberg, K., Stavros, C., \& Robinson, L. J. (2017). Family decision-making in an emerging market: Tensions with tradition. Journal of Business Research, (in this issue).

Nguyen, N. N., Özçaglar-Toulouse, N., \& Kjeldgaard, D. (2017). Toward an understanding of young consumers' daily consumption practices in post-Doi Moi Vietnam. Journal of Business Research, (in this issue).

Nyadzayo, M. W., Matanda, M. J., \& Rajaguru, R. (2017). The determinants of franchise brand loyalty in B2B markets: An emerging market perspective. Journal of Business Research, (in this issue). 
Pels, J., \& Sheth, J. N. (2017). Business models to serve low-income consumers in emerging markets. Marketing Theory. doi:http://journals.sagepub.com/doi/abs/10.1177/1470593117704262

Rostow, W. W. (1960). The Stages of Economic Growth: A Non-communist Manifesto. New York: Cambridge University Press.

Roy, S. K., Balaji, M., Soutar, G., Lassar, W. M., \& Roy, R. (2017). Customer engagement behavior in individualistic and collectivistic markets. Journal of Business Research, (in this issue).

Samli, A. C., \& Hassan, S. S. (1992). International Segmentation Options: Getting Away From Conventional Wisdom. Developments in Marketing Science, 15, 185-188.

Shamah, R. A. M., Mason, M. C., Moretti, A., \& Raggiotto, F. (2017). Investigating the antecedents of African fast food customers' loyalty: A self-congruity perspective. Journal of Business Research, (in this issue).

Sharma, P. (2011). Country-of-Origin Effects in Developed vs. Emerging Markets: Exploring the Contrasting Roles of Materialism and Value-Consciousness. Journal of International Business Studies, 42(2), 285-306.

Sheth, J. N. (2011). Impact of emerging markets on marketing: Rethinking existing perspectives and practices. Journal of Marketing, 75(4), 166-182.

Sinha, M., \& Sheth, J. (2017). Growing the pie in emerging markets: Marketing strategies for increasing the ratio of non-users to users. Journal of Business Research, (in this issue). 
Smirnova, M. M., Rebiazina, V. A., \& Frösén, J. (2017). Customer orientation as a multidimensional construct: Evidence from the Russian markets. Journal of Business Research, (in this issue).

Sok, P., O'Cass, A., \& Miles, M. P. (2015). The Performance Advantages for SMEs of Product Innovation and Marketing Resource-Capability Complementarity in Emerging Economies. Journal of Small Business Management.

Strizhakova, Y., Coulter, R. A., \& Price, L. L. (2012). The young adult cohort in emerging markets: Assessing their glocal cultural identity in a global marketplace. International Journal of Research in Marketing, 29(1), 43-54.

Sun, L., Zheng, X., Su, M., \& Keller, L. R. (2017). Intention-Behavior Discrepancy of Foreign Versus Domestic Brands in Emerging Markets: The Relevance of Consumer Prior Knowledge. Journal of International Marketing, 25(1), 91-109.

Tanusondjaja, A., Greenacre, L., Banelis, M., Truong, O., \& Andrews, T. (2015). International brands in emerging markets: the myths of segmentation. International Marketing Review, 32(6), 783-796.

Tse, D. K., Belk, R. W., \& Zhou, N. (1989). Becoming a consumer society: A longitudinal and cross-cultural content analysis of print ads from Hong Kong, the People's Republic of China, and Taiwan. Journal of Consumer Research, 15(March), 457-472.

Varadarajan, R., \& Kaul, R. (2017). Doing well by doing good innovations: alleviation of social problems in emerging markets through corporate social innovations. Journal of Business Research, (in this issue). 
Wei, Y. S., Samiee, S., \& Lee, R. P. (2014). The influence of organic organizational cultures, market responsiveness, and product strategy on firm performance in an emerging market. Journal of the Academy of Marketing Science, 42(1), 49-70.

Wright, M., Filatotchev, I., Hoskisson, R. E., \& Peng, M. W. (2005). Strategy Research in Emerging Economies: Challenging the Conventional Wisdom. Journal of Management Studies, 42(1), 1-33.

Zarantonello, L., Schmitt, B. H., \& Jedidi, K. (2014). How to Advertise and Build Brand Knowledge Globally: Comparing Television Advertising Appeals across Developed and Emerging Economies. Journal of Advertising Research, 54(4), 420-434.

Zhao, M., Park, S. H., \& Zhou, N. (2014). MNC strategy and social adaptation in emerging markets. Journal of International Business Studies, 45(7), 842-861. 